\title{
LAS TRANSFORMACIONES DEL DERECHO ADMINISTRATIVO. ¿ANTE UN CAMBIO DE ÉPOCA?
}

\author{
The transformations of Administrative Law \\ In the face of a change of time? \\ Le trasformazioni del Diritto Amministrativo \\ Di fronte a un cambiamento di tempo?
}

Ignacio M. de la Riva ${ }^{1}$

Para citar este artículo:

de la Riva, I. M. (2020). "Las transformaciones del derecho administrativo ¿ante un cambio de época?”. Prudentia Iuris, N. Aniversario, pp. 235-249.

DOI: https://doi.org/10.46553/prudentia.aniversario.2020.pp.235-249

Resumen: El Derecho Administrativo nació en un contexto preciso, el de la Francia posrevolucionaria de fines del siglo XVIII. La teoría de la separación de poderes y el principio de legalidad estuvieron a la base de la novel rama, forjada por la labor jurisprudencial desplegada por el Consejo de Estado francés. Su evolución posterior se mantuvo siempre ligada a los avatares económicos, políticos y sociales, y hoy se enfrenta a un escenario signado por un nuevo modo de relacionamiento entre el Estado y la Sociedad, un reposicionamiento de los tres órganos del sistema tripartito de poderes, un creciente influjo de las instancias internacionales sobre las estatales, y un fuerte impacto de los avances tecnológicos sobre la Administración pública. Todos estos cambios están haciendo crujir la estructura histórica del

1 Doctor en Derecho por la Universidad de Valladolid, Valladolid, España. Desde el año 2005 a la actualidad es socio en el estudio Cassagne Abogados. Desde el año 2003 es Profesor Titular en la Carrera de Posgrado Especializado en Derecho Administrativo Económico, de la Universidad Católica Argentina, Buenos Aires, Argentina. Correo electrónico: ignaciodelariva@uca.edu.ar. 
Derecho Administrativo, y obligan a repensar el alcance de sus categorías clásicas con vistas a aggiornarlas al presente statu quo.

Palabras clave: Derecho Administrativo; Administración pública; Principio de legalidad; Principio de subsidiariedad; Derecho Administrativo global.

\begin{abstract}
Administrative Law was born in a precise context, that of postrevolutionary France at the end of the 18th century. The theory of the separation of powers and the principle of legality were at the base of the new branch, forged by the jurisprudential work carried out by the French Council of State. Its subsequent evolution was always linked to economic, political and social vicissitudes, and today it faces a scenario marked by a new way of relating between the State and Society, a repositioning of the three organs of the tripartite system of powers, a growing influence of international instances on state ones, and a strong impact on public administration of technological advances. All these changes are making the historical structure of Administrative Law crunch, and they force us to rethink the scope of its classic categories with a view to adjust them to the present status quo.
\end{abstract}

Keywords: Administrative Law; Public administration; Principle of legality; Principle of subsidiarity; Global Administrative Law.

Sommario: Il Diritto amministrativo nacque in un preciso contesto, quello della Francia post-rivoluzionaria alla fine del XVIII secolo. La teoria della separazione dei poteri e il principio di legalità erano alla base del nuovo ramo, forgiato dal lavoro giurisprudenziale svolto dal Consiglio di Stato francese. La sua successiva evoluzione fu sempre legata alle vicissitudini economiche, politiche e sociali, e oggi affronta uno scenario segnato da un nuovo modo di relazionarsi tra Stato e Società, un riposizionamento dei tre organi del sistema tripartito di poteri, una crescente influenza degli enti internazionali sullo stato, e un forte impatto dei progressi tecnologici sulla pubblica amministrazione. Tutti questi cambiamenti stanno causando il crollo della struttura storica del Diritto amministrativo e ci stanno costringendo a ripensare le sue categorie classiche al fine di adattarli allo status quo attuale.

Parole chiave: Diritto Amministrativo; Pubblica amministrazione; Principio di legalità; Principio di sussidiarietà; Diritto Amministrativo globale. 


\section{Aclaración preliminar}

El título del presente trabajo podría crear en el lector una expectativa desmedida, induciéndolo a pensar que habrá de encontrarse con un diagnóstico cabal de la problemática planteada, lo cual excedería no solo el acotado marco de este escrito, sino también las posibilidades de su autor. Las breves páginas que siguen responden, más bien, al modesto deseo de compartir algunas reflexiones personales sobre tan basta y compleja cuestión, en el convencimiento de que los cambios que hoy experimenta el Derecho Administrativo reclaman una discusión atenta de la comunidad científica, para una mejor comprensión de su alcance y significado.

Es cierto que la incesante evolución a la que, desde sus mismos orígenes, está sujeta esta novel rama jurídica (calificativo absolutamente pertinente si se la compara, al menos, con la trayectoria varias veces milenaria registrada por el Derecho Civil), ha concitado recurrentemente la atención de sus estudiosos más destacados ${ }^{2}$. El fenómeno, sin embargo, queda siempre abierto a nuevos análisis, dada la naturaleza intrínsecamente fluyente de la historia de las instituciones.

\section{El Derecho Administrativo como categoría histórica. Su origen y evolución}

El Derecho Administrativo es habitualmente calificado como una categoría histórica ${ }^{3}$, para significar que sus instituciones son hijas del tiempo de su creación y van evolucionando según las condiciones político-sociales de cada época.

Su nacimiento se produce en un contexto en el que confluyen, en el plano político, el auge de las ideas revolucionarias francesas, impulsadas por la Ilustración, que emergen a modo de violenta reacción contra el absolutismo

2 Baste recordar, a modo de ejemplo, la clásica obra de León Duguit, Las transformaciones del Derecho Público, aparecida inicialmente en 1914, cuya traducción al español por A. Posada y R. Jaén fue publicada por Editorial Heliasta en 1975.

3 Cassagne, J. C. (2018). Curso de Derecho administrativo. T. I. $12^{a}$. edición actualizada. Buenos Aires. Thomson Reuters - La Ley, 79-83; y Santamaría Pastor, J. A. (2001). Principios de Derecho Administrativo. Volumen I. $3^{\text {a }}$ edición. Madrid. Editorial Centro de Estudios Ramón Areces S.A., 45-47. De allí el énfasis que la doctrina ha puesto en destacar la utilidad y pertinencia del método histórico para la ciencia del Derecho Administrativo [cfr. Fernández Farreres, G. (2016). Sistema de Derecho Administrativo. T. I. $3^{\text {a }}$ edición. Pamplona. Thomson Reuters - Civitas, 93-97]. 
monárquico entonces imperante, y los resabios del abrupto cambio de escenario socio-económico derivado de la Revolución Industrial ${ }^{4}$.

La primera de dichas dimensiones ha sido magistralmente retratada por García de Enterría, en su clásico opúsculo Revolución Francesa y Administración contemporánea, en el que pone en claro que la formulación del principio de legalidad, como expresión técnico instrumental de la concepción rousseauniana de la soberanía del pueblo, constituye uno de los pilares sobre los cuales se asentó el incipiente Derecho Administrativo de comienzos del siglo XIX. El lugar central ocupado por dicho principio se manifiesta no sólo en la identificación de la ley como garante de la libertad de los individuos, sino también en su consideración como fuente habilitante (y límite) del ejercicio de todo poder público que se traduzca en el dictado de los actos singulares que emanan del gobierno y de los tribunales ${ }^{5}$.

Sin desconocer la primacía de la ley, a su vez, el mencionado autor destaca como otro componente esencial del Derecho Administrativo primigenio la estructura del Estado surgida al influjo de la separación de funciones postulada por Locke y por Montesquieu, la cual da cabida a la nítida distinción entre el dictado de las leyes, su ejecución a través del empleo de la coacción y la tarea de impartir justicia ${ }^{6}$.

Sobre esas premisas, aunque a partir de una peculiar interpretación del principio de separación de poderes, Francia avanzó por un derrotero propio, distinto al seguido por el mundo anglosajón frente a idéntico punto de partida ${ }^{7}$, lo cual desembocó en suelo galo en el alumbramiento de una notable Administración pública, dotada de unas prerrogativas públicas aún más poderosas que las del Antiguo Régimen, destronado por los revolucionarios ${ }^{8}$.

4 José L. Villar Palasí, sin embargo, sin dejar de reconocer el decisivo impulso que recibió esta rama del Derecho Público en el período que sucedió a la Revolución Francesa, destaca que su conformación es resultado de un proceso de decantación que arranca varios siglos antes, con aportaciones provenientes del Derecho romano, del Derecho Canónico y del Derecho Regio (ver su Curso de Derecho Administrativo. Tomo I. Madrid, 1972, 82-84).

5 García de Enterría, E. (1994). Revolución Francesa y Administración contemporánea. $4^{\text {a }}$ edición. Madrid. Civitas, 21-28.

Con razón señala José Luis Martínez López-Muñiz que el Estado y los distintos Poderes públicos no dejan de ser organizaciones "artificiales" e instrumentales para la consecución de los fines que las justifican; entidades serviciales, al servicio de los derechos fundamentales de quienes las constituyen [cfr. su trabajo (abril-junio 2019). "Para evitar la degradación del Estado de Derecho". En Revista española de Derecho Administrativo, núm. 198, 15].

6 Ídem, 28-34.

7 Bianchi, A. B. (2019). La separación de poderes. (Un estudio desde el Derecho Comparado). Buenos Aires. Cathedra Jurídica, 46-77 y 104-110.

8 Ídem, 37-51. 
Como resultado de este dinamismo surgió la necesidad de establecer, en sintonía con la idea de Estado de Derecho esbozada por los pensadores alemanes a fines del siglo XVIII ${ }^{9}$, un Derecho especial al que quedara sometida esa formidable manifestación de poder público en manos de los órganos ejecutivos, dando así origen a un régimen caracterizado por la exorbitancia de sus principios y criterios estructurantes, si se los compara con aquellos que priman en el resto del ordenamiento ${ }^{10}$.

Las categorías formales que acompañaron la irrupción de esta rama jurídica en el ocaso del siglo XVIII (la teoría de la separación de poderes, el principio de legalidad, la declamación de los derechos inalienables de las personas) fueron enriquecidas, más adelante, merced a los aportes realizados desde una perspectiva más atenta a la dimensión material de los derechos fundamentales en juego, nutrida de concepciones de raíz personalista que, a lo largo de los años, se tradujeron en otros tantos principios y garantías derivados de la dignidad del hombre, hoy plenamente incorporados al Derecho Público (principios pro homine, pro libertate y pro actione, la tutela judicial efectiva, o una más plena responsabilidad del Estado) ${ }^{11}$.

En esta segunda etapa de la evolución del Derecho Administrativo, el factor político queda relegado a un segundo plano, en tanto lo que prima es, más bien, el contexto económico-social gestado como resabio de la Revolución Industrial. Se abre camino, de este modo, un nuevo paradigma, a partir del paso del Estado liberal o gendarme al Estado social o de bienestar. Se trata de una fase signada por un notorio auge de los poderes de intervención

9 Cassagne, J. C. Curso de Derecho Administrativo. T. I. Ob. cit., 18-20.

10 Resulta interesante, en este sentido, la observación expuesta por Germán Fernández Farreres, en cuanto a que el Derecho Administrativo nace, en rigor, de la puja planteada en su día entre los Poderes Ejecutivo y Judicial, de la cual sale fortalecido el primero al lograr, inicialmente, quedar exento del control de los jueces, para conquistar, luego, su sometimiento a una jurisdicción especial que le fue reconociendo los privilegios e inmunidades (y sus correlativos límites y garantías en favor de los particulares) que configuran la esencia del Derecho Administrativo que hoy conocemos (ver su obra Sistema de Derecho Administrativo. Ob. cit., 98-101).

También Jean Rivero destaca el lugar decisivo que ha ocupado la existencia de una jurisdicción administrativa distinta de la jurisdicción judicial en la formación del Derecho Administrativo, pues observa que la tendencia natural del juez judicial lo hubiese llevado a aplicar a los litigios administrativos las reglas del Derecho que le eran familiares, es decir, las del Derecho Privado [ver su libro (2019). Derecho Administrativo. Traducción de la $9^{a}$ edición de su Droit administratif, dirigida por Luigi Garofalo y al cuidado de Carlos Antonio Agurto Gonzáles, Sonia Lidia Quequejana Mamani y Benigno Choque Cuenca. Santiago de Chile. Ediciones Olejnik, 55].

11 Cassagne, J. C. Curso de Derecho Administrativo. T. I. Ob. cit., 20-22. 
pública en la arena económica, los que se incrementarán a un ritmo sostenido desde fines del siglo XIX hasta el último cuarto del siglo $\mathrm{XX}^{12}$.

En el tramo final de la centuria pasada, el generalizado repliegue de los poderes públicos en el campo económico y social inaugura una nueva fase, a la que Cassagne tipifica como la del Estado subsidiario ${ }^{13}$, en razón del evidente influjo del principio de subsidiariedad en la configuración del rediseño de las relaciones entre lo público y lo privado, cuyo punto de equilibrio está aún en vías de hallarse.

\section{Replanteamiento de la relación entre el Estado y la sociedad}

Durante ese último tramo, es indudable que el sector privado ha recuperado espacio frente a un Estado que había ido avanzando en la escena económica a lo largo de más de un siglo ${ }^{14}$. El impacto en el Derecho Administrativo de tal desplazamiento es notorio, lo que justifica considerarlo en primer lugar.

Este movimiento pendular no importa un regreso al Estado gendarme, puesto que no postula un Estado ausente (como alguna vez se ha creído), sino un mero cambio de su localización en la arena económica, concretizado a través de un extendido abandono de sus funciones prestacionales para asumir el papel de regulador y fiscalizador, y garante del interés público ${ }^{15}$.

En este nuevo entorno, las relaciones entre Estado y sociedad se intentan abordar más en términos de encuentro y cooperación recíprocos, y no tan sólo desde la oposición y la tensión entre ambos polos. Es interesante porque esto propone un nuevo eje de reflexión del Derecho Administrativo,

12 Cfr. mi libro (2004). Ayudas públicas. (Incidencia de la intervención estatal en el funcionamiento del mercado). Buenos Aires. Hammurabi, 57-64.

13 Cassagne, J. C. Curso de Derecho Administrativo. T. I. Ob. cit., 46-50.

14 En palabras de Juan Carlos Cassagne, "se ha operado un cambio en los protagonistas del Derecho Público, potenciándose el rol de la sociedad que, de mera espectadora de la realidad, pasa a cumplir funciones relevantes, en colaboración estrecha con la Administración pública". Ver su artículo "Sobre las transformaciones del Derecho Público: Hacia un Estado regulador y garante. (Nuevos y antiguos problemas)", en La Ley, edición del 4 de noviembre de 2019,1 .

15 Entre quienes se han ocupado de estudiar y describir recientemente este proceso, ocupa un lugar destacado José Esteve Pardo, quien ha dedicado distintos trabajos a la cuestión. Cito, por todos, su libro (2013). La nueva relación entre Estado y sociedad. (Aproximación al trasfondo de la crisis). Madrid. Marcial Pons. En ese libro, el autor califica el modelo resultante como Estado regulador y garante, cuyas características Cassagne juzga equiparables a las del Estado subsidiario por él acuñado décadas atrás (cfr. "Sobre las transformaciones del Derecho Público...", cit., 2 y 4). 
pues a la par de los principios de legalidad y de separación de poderes, se ha venido a añadir lo atinente a la distribución de incumbencias entre los ámbitos público y privado, problema que trae a la escena con fuerza el principio de subsidiariedad ${ }^{16}$.

Semejante reposicionamiento trajo consigo, como es natural, la necesidad de aggiornar las clásicas técnicas de intervención pública ${ }^{17}$. Al hilo de esta honda transformación, se advierte una disminución de la actuación imperativa unilateral que primaba en los orígenes del Derecho Administrativo, y un correlativo aflorar de variantes participativas y concertadas, que trascienden largamente la técnica contractual ${ }^{18} \mathrm{y}$, en particular, su modalidad concesional ${ }^{19}$. Para afrontar sus cometidos, la Administración acude

16 Barnés, J. (2003). En su "Presentación de la traducción" al libro de Eberhard Schmidt-Assmann. La teoría general del Derecho Administrativo como sistema. Madrid-Barcelona. Instituto Nacional de Administración Pública - Marcial Pons, XXIV. El propio Eberhard Schmidt-Assmann, en su libro recién citado, al referirse a este fenómeno hace alusión, indistintamente, al "Estado cooperativo" y a la "Administración cooperativa", en cuyo seno la tradicional modalidad jerárquica de actuación es reemplazada por instrumentos basados en la cooperación y el consenso (ob. cit., 38-40). El autor pone en evidencia que la colaboración a la que se refiere no se circunscribe, desde luego, al terreno económico, y lo ejemplifica a través del examen de cuanto viene ocurriendo en el plano medioambiental, de la asistencia social y de la actividad científica (ob. cit., 134-157).

17 Carro Fernández-Valmayor, J. L. (enero-abril 2014). "Reflexiones sobre las transformaciones del Derecho Público, en especial del Derecho Administrativo". En Revista de Administración Pública, núm. 193, 35-36. La figura que primero nos vendrá en mente, en este sentido, probablemente sea la del servicio público. La ola privatizadora de fines del siglo XX ha generado un caudal de literatura jurídica inaudito, dirigido a reflexionar sobre esta técnica interventora desde una perspectiva del todo novedosa, inspirada por los avances de la ciencia económica en materia de regulación económica. El número de obras y trabajos sobre esta cuestión, en el ámbito local y comparado, es inabarcable. Baste con citar, a título ilustrativo, los magníficos diez volúmenes publicados en su día con la dirección de Muñoz Machado, S. (2010). Derecho de la regulación económica. Madrid. Iustel.

Pero los ejemplos no se agotan allí. En el terreno del dominio público (entre otros) puede decirse otro tanto. En los últimos años se viene evidenciando un replanteamiento análogo, tendiente a conjugar las restricciones inherentes a esta histórica categoría con la necesidad de introducir criterios más flexibles que habiliten una mayor interacción con los particulares, con vistas a preservar y sacar mejor provecho del ingente patrimonio estatal involucrado. Me he ocupado del tema en mi trabajo (2017). "El clásico dominio público frente a los aires que propician su valorización”. En AA. VV. Derecho Administrativo e integración europea. (Estudios en homenaje al Profesor José Luis Martínez López-Muñiz). Con la coordinación de José Carlos Laguna de Paz, Ínigo Sanz Rubiales e Isabel María de los Mozos y Touya. Madrid. Reus, 12591275 , al cual remito.

18 Muñoz Machado, S. (2015). Tratado de Derecho Administrativo y Derecho Público general. T. I. $4^{a}$ edición. Madrid. Agencia Estatal Boletín Oficial del Estado, 60-68; y Sánchez Morón, M. (2019). Derecho Administrativo (Parte general). 15 ${ }^{\text {a }}$. edición. Madrid. Tecnos, 55-56.

19 La figura de la concesión ha sido, como es sabido, el instrumento típicamente empleado desde el siglo XIX para dar cauce a la colaboración de los privados en la construcción de 
hoy con asiduidad a figuras asociativas, que facilitan la confluencia virtuosa de impulsos nacidos desde las órbitas pública y privada, o a instancias que dependen del voluntario acatamiento de los sectores implicados.

Por solo citar algunos ejemplos, cabe mencionar el auge alcanzado por los contratos de "PPP" ("participación público-privada"); el creciente empleo de la categoría de los Derechos Reales Administrativos para brindar un marco más sólido a la intervención privada en la explotación de bienes del dominio público; la habitualidad con que los privados son convocados a desempeñar tareas de fiscalización e inspección otrora monopolizadas por los agentes públicos; la variedad de situaciones en las que la actividad regulatoria en manos de autoridades públicas requiere transitar instancias de consulta obligatoria a los particulares afectados; el reemplazo extendido de la técnica autorizatoria por meras declaraciones juradas de los sujetos involucrados (a título de comunicaciones previas o declaraciones responsables); o el avance de la autorregulación en diversos sectores de la economía.

Las novedades apuntadas obligan -qué duda hay- a reconsiderar el alcance y los perfiles históricos de las tradicionales prerrogativas públicas, en orden a amoldarlas a la creciente interacción entre los sujetos públicos y privados y a la más amplia participación de los últimos, que trae consigo una inevitable mayor exposición de sus personas y patrimonios. La cuestión es cómo lograrlo sin dejar desprotegido el interés general comprometido ${ }^{20}$.

Los cambios descriptos en el terreno de las relaciones entre el Estado y la sociedad dan cuenta, también, del ensanche experimentado por las fronteras del Derecho Administrativo, cuyo ámbito de aplicación se ha extendido más allá de los espacios y relaciones que involucran, estrictamente, a la Administración pública, para proyectarse sobre situaciones que evidencian el ejercicio de funciones administrativas en casos en que aquélla no está directamente implicada. De este modo, la problemática que hoy afronta esta rama del Derecho no se limita a proteger a los individuos frente al ejercicio

obras públicas y en la gestión de servicios públicos. Ver, al respecto, Montaña, A. y Castaño, D. (2018). "Delimitación de la contribución del contrato de concesión de servicio público a la formación del Derecho Administrativo nacional a partir de la revisión de sus influencias foráneas: la tradicional francesa y la alternativa estadounidense". En AA. VV. El Derecho Administrativo como idea y sus transformaciones contemporáneas. Daniel Castaño (editor). Bogotá. Universidad Externado de Colombia, 51-59.

20 En particular, esta necesaria revisión no debe alentar el fenómeno, tan extendidamente observado, de la "huida del Derecho Administrativo", que no es sino una versión deformada de ese reposicionamiento que se verifica cuando la Administración decide someter su actuación típicamente pública a formatos institucionales o diseños regulatorios propios del ámbito privado, en procura de eludir los controles y limitaciones que el Derecho Público impone a su accionar en salvaguarda de los intereses públicos en juego. En igual sentido, cfr. Santamaría Pastor, J. A. Principios de Derecho Administrativo. Volumen I. Ob. cit., 79-80. 
inmoderado del poder estatal, sino que atiende, también, conflictos suscitados por el abuso de posiciones de poder detentadas por particulares ${ }^{21}$.

\section{Cambios en la esfera Estatal. Evolución del sistema de separación de poderes}

El desplazamiento de la línea fronteriza entre las incumbencias públicas y privadas descripto en el punto anterior estuvo precedido, como ya se indicó, por una sostenida expansión estatal en el campo económico, entre fines del siglo XIX y la década del ochenta del siglo XX. Como es natural, las tareas inherentes a esta extendida injerencia pública recayeron, sustancialmente, en la Administración pública, que creció considerablemente en tamaño e importancia.

La ejecución de esos crecientes quehaceres incorporados a la esfera estatal no podía quedar sujeta al corsé de un marco legal estático, incapaz de dar respuesta oportuna al sinfín de dificultades cambiantes que genera el dinamismo económico ${ }^{22}$. De allí que el principio de legalidad como eje rector estricto de la relación entre legislador y órgano ejecutivo se fuera diluyendo, dando lugar a que, a la par de la ley formal, surgieran otras fuentes productoras de normas generales de idéntico e superior rango, como es el caso de los instrumentos convencionales ${ }^{23}$. Este profundo cambio se reflejó, incluso, en los textos constitucionales, que habilitaron de modo explícito al Poder Ejecutivo a producir disposiciones con jerarquía de ley, a través de decretos de necesidad y urgencia, y decretos delegados.

21 Esteve Pardo, J. La nueva relación entre Estado y sociedad... Ob. cit., 183-188 y 192-205.

En este sentido, se ha destacado la idoneidad del Derecho Público para regular todo tipo de situaciones de poder, las que pueden verificarse también en el marco de relaciones jurídicoprivadas, en tanto afecten de manera negativa el interés público, sea que los sujetos privados ejerzan funciones estrictamente administrativas o lleven a cabo cometidos de interés general (cfr. Carro Fernández-Valmayor, J. L. "Reflexiones sobre las transformaciones del Derecho Público...", cit., 26-27).

22 Eberhard Schmidt-Assmann reconoce las dificultades que existen para reconducir a programas abstractos de formulación apriorística plasmados en un texto legal a la dinámica de actuación propia del Estado social prestacional, pese a lo cual no reniega del lugar que ocupa la ley como la piedra angular insustituible del Derecho Administrativo (ver su libro, La teoría general del Derecho Administrativo como sistema, cit., 93). El autor advierte, sin embargo, sobre la importancia de dotar de autonomía (discrecionalidad) al órgano ejecutivo, y apela a tal fin a la sugerente imagen de la Administración dirigida por la ley a efectos de situarla a mitad de camino entre una Administración completamente predeterminada por el legislador y una Administración libre de toda dirección legal (ob. cit., 211-214).

23 Muñoz Machado, S. Tratado de Derecho Administrativo y Derecho Público general. T. I. Ob. cit., 58-59. 
También los jueces fueron incrementando su peso relativo y su margen de discrecionalidad como intérpretes y responsables de la aplicación de la ley. Aquella independencia ganada por la Administración respecto del legislador no podía sino repercutir en una mayor autonomía de los tribunales frente a una Administración que ya no aparece ceñida a la ley con la misma rigidez. Los principios generales del Derecho cobraron, a partir de entonces, un vigor y centralidad que habían perdido, y los jueces se convirtieron, así, en genuinos creadores del Derecho, potenciados por su condición de últimos intérpretes de la Constitución, más atentos a preservar la justicia material que a velar por el cumplimiento de condicionamientos formales, con las ventajas y riesgos que ello comporta ${ }^{24}$.

Cuanto se viene exponiendo exhibe la presencia de numerosos síntomas que denotan la crisis por la que atraviesa el principio de separación de poderes. Ella no se reduce, por cierto, al desplazamiento de poder que se evidencia entre los titulares de las distintas funciones, sino que concurren también factores exógenos al principio, como es el caso del debilitamiento de facto de los controles recíprocos (en particular, entre los órganos ejecutivo y legislativo), debido a la incidencia de la disciplina impuesta por los partidos políticos, y a las crecientes relaciones que median entre los detentadores del poder público y los operadores privados ${ }^{25}$.

Pese a todo, debe reconocerse que la lógica de los frenos y contrapesos ínsita en el sistema de separación de poderes sigue vigente ${ }^{26}$, aun cuando el equilibrio de fuerzas entre los distintos órganos que lo integran se ha rediseñado, a expensas de la preeminencia del Poder Legislativo frente a los

24 Para ampliar, remito al profundo análisis del tema abordado por Valentín Thury Cornejo en su tesis doctoral, publicada con el título (2002). Juez y división de poderes hoy. Buenos Aires - Madrid. Ciudad Argentina. Ver, en particular, 233-238.

Esta prominente participación asumida por los jueces en el juego del poder fraccionado plantea, también, nuevos desafíos al Derecho Administrativo. Uno de los problemas que obliga a afrontar viene dado por el hecho de que la labor judicial, basada en la resolución de casos, está primordialmente orientada a la tutela de los Derechos Subjetivos (por definición, de carácter individual), lo cual coloca al juez en una perspectiva claramente distinta a la del funcionario administrativo, quien toma sus decisiones a partir de la valoración de un contexto más amplio de sujetos y factores, ajenos, muchos de ellos, a la ponderación judicial. Esto exige un replanteamiento de las reglas del proceso, lo cual se torna particularmente acuciante en el caso de los procesos colectivos. Recomiendo, sobre estos temas, la lectura de Schmidt-Assmann, E. La teoría general del Derecho Administrativo como sistema. Ob. cit., 239-245.

25 Schmidt-Assmann, E. La teoría general del Derecho Administrativo como sistema. Ob. cit., 192.

26 Tal como lo señala el autor citado en la nota anterior, la finalidad primordial de la teoría, cual es la de procurar la racionalidad del actuar público a través de estructuras diferenciadas, se mantiene en pie (ob. cit., 193). 
dos restantes y en consonancia con una participación más activa del sector privado en el ejercicio de ciertos cometidos públicos.

\section{Incidencia de los cambios tecnológicos: hacia un nuevo modelo de Administración pública}

Los avances que se vienen produciendo en el terreno de las tecnologías, en particular de aquellas que facilitan el acceso y el flujo de la información, tienen también un indudable influjo sobre el modo de ejercer la función administrativa y, por ende, sobre el propio Derecho Administrativo. La inteligencia artificial aplicada a la gestión pública permite, cada vez más, tomar decisiones de manera automatizada y a partir del procesamiento de una cantidad de datos inaudita.

Las transformaciones a que ello da lugar se verifican en distintos planos, creando nuevos desafíos, pero también oportunidades para mejorar la agilidad, eficacia y transparencia de las prestaciones que brinda la Administración, a partir del desarrollo de un modelo de administración electrónica (e-administration) que saque provecho de las tecnologías de la información y de las comunicaciones ${ }^{27}$.

Por solo mencionar algunas de sus consecuencias más notorias, son bien conocidos los cambios que se han producido en materia de procedimiento administrativo, que ha ido abandonando su histórica dependencia del papel para migrar hacia una modalidad que descansa, de manera creciente, en el formato digital, que contribuye a la celeridad y transparencia de los trámites. Ello ha exigido ciertas enmiendas normativas, con especial referencia al régimen de acceso a las actuaciones, a su circulación entre las oficinas públicas, o a la forma en que se instrumentan las notificaciones, entre otras cuestiones.

Otro terreno que exhibe profundos cambios es el de la contratación pública, donde la incorporación de modalidades virtuales ha resultado, asimismo, en beneficio de una mayor transparencia (dada la más extendida publicidad que conlleva) y en un plus de eficiencia.

Esta expansión de los medios tecnológicos presenta y agudiza, a la vez, nuevos problemas para el Derecho Administrativo ${ }^{28}$, como los vinculados a la necesidad de diseñar políticas de protección de datos personales, para no afectar el derecho a la privacidad; o el deber de garantizar la igualdad

27 Sánchez Morón, M. Derecho Administrativo (Parte general). Ob. cit., 62-63.

28 Ya se habla, incluso, de un Derecho Administrativo de la información (cfr. SchmidtAssmann, E. La teoría general del Derecho Administrativo como sistema. Ob. cit., 293). 
de acceso a todos los ciudadanos a la información disponible en las nuevas plataformas.

\section{Atenuación de la impronta local del Derecho Administrativo frente al creciente influjo de las normas internacionales}

Ante la globalización de los flujos económicos y la proliferación de iniciativas de integración regional, los sistemas nacionales de Derecho Administrativo, independientes entre sí, se mueven en dirección a su recíproca coordinación. Tal fenómeno es favorecido por la creación de instancias supranacionales y la construcción de un Derecho Administrativo global, cuyas normas y directivas van penetrando en los ordenamientos locales, dando por resultado su progresiva armonización ${ }^{29}$. Ello resulta una novedad absoluta frente a un Derecho Administrativo caracterizado históricamente como eminentemente local, en razón de su fuerte apego a las instituciones propias de cada país ${ }^{30}$.

Este proceso se verifica en dos órdenes y con niveles de intensidad diferentes. De un lado, están los acuerdos internacionales, situados en el plano de la estricta cooperación internacional. A través de ellos los gobiernos estatales asumen una serie de compromisos, plasmados en los textos respectivos. Pero a ello se añade la dimensión supranacional, propia de los tratados de integración, que supone la delegación de ciertas competencias a los órganos nacidos de dichos tratados, de modo que algunas de las normas y decisiones que emanan de aquéllos producen efectos directos dentro de

29 Meilán Gil, J. L. (2016). Derecho Administrativo revisado. Santiago de Compostela. Andavira Editores, 26-33.

30 El fenómeno descripto ha contribuido, sin duda, a morigerar la enorme distancia que existía, en sus orígenes, entre el régimen administrativo y el Derecho común (common law). El primero, definido como un Derecho especial para gobernar las relaciones entabladas por los Poderes públicos (en particular, aquellos que integran la Administración pública), cuya aplicación quedaba en manos de órganos de la misma órbita administrativa (como el Consejo de Estado francés) o de tribunales especializados (con competencia contencioso administrativa), se propagó entre los países de Europa continental, y más tarde por Latinoamérica. El mundo anglosajón, en cambio, se mostró inicialmente refractario a la idea de someter a la Administración a normas y a jueces diferentes a los del resto de las personas (cfr. Sánchez Morón, M. Derecho Administrativo (Parte general). Ob. cit., 46-51). Esta contraposición tan extrema entre ambos sistemas se fue atenuando con el tiempo a partir de su influencia recíproca, decantando hacia su paulatina convergencia. Tal aproximación comenzó mucho antes de que emergiera la dinámica de integración que aquí se señala, pero es innegable que esta última ha impulsado ese proceso de armonización hasta niveles insospechados. 
los territorios nacionales abarcados ${ }^{31}$. Ambas variantes traen consigo consecuencias palpables en dirección a la progresiva armonización y homogeneidad de los Derechos Administrativos nacionales.

Esta creciente simbiosis del Derecho Administrativo, cada vez menos respetuoso de las idiosincrasias nacionales, ha cobrado dimensión universal, dando origen al llamado Derecho Administrativo global ${ }^{32}$. Más allá de los matices y reparos que quepa oponer a tan ampuloso calificativo, es forzoso reconocer la presencia de un entramado de normas a nivel planetario, que despunta con fuerza irresistible en algunos terrenos en particular, donde los flujos económicos o los bienes públicos en juego revisten ese mismo alcance mundial. Así ocurre con la protección del medio ambiente, con la seguridad pública y ciertos aspectos de la sanidad pública, con la contratación pública, o con la operatoria financiera, por mencionar solo algunos ejemplos. Las soluciones locales frente a tales problemas se muestran cada vez más insuficientes e ineficaces, lo cual obliga a buscar consensos que permitan ir diseñando respuestas globales, en las que los instrumentos internacionales y las normativas locales vayan en la misma dirección.

De todas maneras, en modo alguno estos entramados normativos supra e internacionales logran reemplazar a los ordenamientos nacionales, al menos en el estado actual de configuración del concierto de las naciones. Las normas que provienen de aquellos estratos, además de fragmentarias, carecen muchas veces de fuerza vinculante (pertenecen a lo que se conoce como soft law), y emanan de acuerdos colaborativos entre Estados soberanos o de directivas producidas por órganos que no están dotados de imperium para imponerlas, y que adolecen, además, con frecuencia, de legitimidad democrática.

\section{Balance y perspectivas}

Las transformaciones que han sido apenas apuntadas confirman la incesante evolución del Derecho Público. En ese permanente fluir de sus instituciones inciden una multiplicidad de factores, todos en algún punto interconectados, desde los reacomodamientos políticos (en la órbita nacional y transnacional), a los ciclos económicos y los avances tecnológicos, tamizados todos ellos por aportes realizados desde el pensamiento jurídico y filosófico.

31 Ver mi libro Ayudas públicas. (Incidencia de la intervención estatal en el funcionamiento del mercado). Ob. cit., 291-296.

32 Kingsbury, B.; Krisch, N. y Stewart, R. B. (2007-3). "El surgimiento del Derecho Administrativo global”. En Res Pública Argentina, 25-74. 
Queda por preguntarnos hasta qué punto los cambios observados nos sitúan o no ante un punto de inflexión que merezca ser considerado como un auténtico cambio de época ${ }^{33}$. ¿Cabe, en efecto, pensar que estamos frente a un quiebre que afecta a las bases mismas del Derecho Administrativo? ¿O, más bien, se trata de mutaciones que hacen a su epidermis? Y si fuera el caso de una transformación de fondo, ¿cuál sería su alcance, su dirección, el significado profundo de tal viraje?

La respuesta cabal a estos interrogantes sólo podrá brindarse, con algún grado de rigor y certeza, con el paso del tiempo, pues solo él confiere la perspectiva necesaria para un análisis objetivo y equilibrado.

Entretanto, podría decirse que la esencia del Derecho Administrativo resiste a los avatares que, innegablemente, experimenta: las prerrogativas públicas, si bien en ocasiones morigeradas, siguen presentes como elemento intrínseco de las relaciones jurídico-públicas; el ejercicio de la función administrativa, aunque eventualmente en manos de sujetos privados, continúa sometido al bloque de legalidad que le sirve de marco; y la lógica que imprime el principio de separación de poderes opera hoy, como antaño, como principal sustrato de las relaciones de control recíproco entre el legislador, la Administración y los jueces.

Todo ello no desmiente, sin embargo, que el enfoque primigenio basado en una radical antinomia entre Estado y sociedad, demasiado concentrado en intentar resolver la tensión entre prerrogativas públicas y garantías particulares, se muestra hoy insuficiente para agotar la problemática del Derecho administrativo, y reclama el complemento de una mirada más proclive a la integración entre lo estatal y lo privado como dos vectores que, cada uno desde su propio ámbito, contribuyen a dar satisfacción a las necesidades del interés público ${ }^{34}$.

\section{Bibliografía}

Barnés (2003). "Presentación de la traducción al libro de Eberhard SchmidtAssmann, La teoría general del Derecho Administrativo como sistema”. MadridBarcelona. Instituto Nacional de Administración Pública - Marcial Pons, XXIV.

33 En términos similares se interroga Fernández Farreres en su Sistema de Derecho Administrativo. T. I. Ob. cit., 103-104.

34 A este respecto, observa José Luis Martínez López-Muñiz que el progreso requiere de la suma del esfuerzo estatal y privado, pues la construcción de una sociedad próspera y vigorosa es fruto, también, y en no menor medida, que del aporte del Estado, de la actividad desplegada por los individuos, las familias, las empresas y las agrupaciones intermedias de toda índole que participan de la vida social [ver su libro (1986). Introducción al Derecho Administrativo. Madrid. Tecnos, 16). 
Bianchi, A. B. (2019). La separación de poderes. (Un estudio desde el Derecho Comparado). Buenos Aires. Cathedra Jurídica.

Carro Fernández-Valmayor, J. L. (enero-abril 2014). "Reflexiones sobre las transformaciones del Derecho Público, en especial del Derecho Administrativo". En Revista de Administración Pública, núm. 193.

Cassagne, J. C. (2018). Curso de Derecho Administrativo. T. I, $12^{\text {a }}$. edición actualizada. Buenos Aires. Thomson Reuters - La Ley.

De la Riva, I. "El clásico dominio público frente a los aires que propician su valorización”. En AA. VV. (2017). Derecho Administrativo e integración europea. (Estudios en homenaje al Profesor José Luis Martínez López-Muñiz). Coordinación de José Carlos Laguna de Paz, Íñigo Sanz Rubiales e Isabel María de los Mozos y Touya. Madrid. Reus, 1259-1275.

De la Riva, I. (2004). Ayudas públicas. (Incidencia de la intervención estatal en el funcionamiento del mercado). Buenos Aires. Hammurabi.

Esteve Pardo, J. (2013). La nueva relación entre Estado y sociedad. (Aproximación al trasfondo de la crisis). Madrid. Marcial Pons.

Fernández Farreres, G. (2016). Sistema de Derecho Administrativo. T. I, $3^{\text {a }}$ edición. Pamplona. Thomson Reuters - Civitas, 93-97.

García de Enterría, E. (1994). Revolución Francesa y Administración contemporánea. $4^{\mathrm{a}}$ edición. Madrid. Civitas, 21-28.

Kingsbury, B.; Krisch, N. y Stewart, R. B. (2007-3). "El surgimiento del Derecho Administrativo Global”. En Res Pública Argentina, 25-74.

León Duguit. Las transformaciones del Derecho Público, aparecido inicialmente en 1914, cuya traducción al español por A. Posada y R. Jaén fue publicada por Editorial Heliasta en 1975.

Martínez López-Muñiz, J. L. (abril-junio 2019). "Para evitar la degradación del Estado de Derecho". En Revista española de Derecho Administrativo, núm. 198.

Meilán Gil, J. L. (2016). Derecho Administrativo revisado. Santiago de Compostela. Andavira Editores.

Montaña, A. y Castaño, D. "Delimitación de la contribución del contrato de concesión de servicio público a la formación del Derecho Administrativo nacional a partir de la revisión de sus influencias foráneas: la tradicional francesa y la alternativa estadounidense". En AA. VV. (2018). El Derecho Administrativo como idea y sus transformaciones contemporáneas. Daniel Castaño (editor). Bogotá. Universidad Externado de Colombia, 51-59.

Muñoz Machado, S. (2015). Tratado de Derecho Administrativo y Derecho Público general. T. I. $4^{\text {a }}$ edición. Madrid. Agencia Estatal Boletín Oficial del Estado, 60-68.

Sánchez Morón, M. (2019). Derecho Administrativo (Parte general). 15a . Edición. Madrid. Tecnos.

Santamaría Pastor, J. A. (2001). Principios de Derecho Administrativo. Volumen I. $3^{\text {a }}$ edición. Madrid. Editorial Centro de Estudios Ramón Areces S.A.

Schmidt-Assmann, E. (2003). La teoría general del Derecho Administrativo como sistema. Madrid. Marcial Pons/Instituto Nacional de Administración Pública.

Thury Cornejo, V. (2002). Juez y división de poderes hoy. Buenos Aires - Madrid. Ciudad Argentina. 